Novel Process for Removal and Recovery of Vapor-Phase Mercury

\author{
Technical Progress Report \\ Covering 1st Quarter FY2000 \\ Contract Number DE-AC22-95PC95257 \\ ADA Project Number 4416 \\ Prepared for \\ AAD Document Control \\ Pittsburgh Energy Technology Center \\ P. O. 10940, MS 921-143 \\ Pittsburgh, PA 15236-0940 \\ Mr. Tony Mayne \\ Contracting Officer's Representative \\ MS 922-260 \\ 412-386-4673 \\ Prepared by \\ ADA Technologies, Inc. \\ 8100 Shaffer Parkway, Suite 130 \\ Littleton, CO 80127
}

January 21, 2000 


\section{Novel Process for Removal and Recovery of Vapor-Phase Mercury}

The purpose of this project is to investigate the application of a sorbent-based process for removing and recovering mercury in the flue gas of coal-fired power plants. The process is based on the sorption of mercury by noble metals and the regeneration of the sorbent by thermal means, recovering the desorbed mercury for recycling. ADA Technologies holds a patent on this process (US 5,409,522) and has tested it under conditions typical of municipal waste incinerators. In this process, the noble metal sorbent is thermally regenerated, and the mercury is recovered for commercial recycle or disposal. ADA has adopted the name "Mercu-RE" to describe its process.

ADA has been testing its process under conditions typical of coal-fired power plants where the mercury concentration is low (below $10 \mu \mathrm{g} / \mathrm{m}^{3}$ ) and little pressure drop can be tolerated. The objective of this program is to develop the Mercu-RE process as a suitable mercury emission control technology for use at coal-fired power plants.

\section{Overview of Progress}

Phase I tasks 1 through 5 were completed as of October 1997. No additional activities have occurred under those tasks. Current period activities are summarized by task:

\section{II-6 Modify 20-acfm Skid}

ADA's modified mercury analyzer has completed its initial tests and is awaiting the opportunity for trials at the field site. ADA delayed using it at Hudson because of the poor skid performance and need for additional sorbent testing in the lab. Opportunities for field demonstration are being pursued.

\section{II-7 Establish Routine Operation at Pilot Combustor}

No work this task during this quarter.

\section{II-8 Install and Shakedown Pilot System at Utility Site}

At the end of March 1999 the equipment skid was relocated to Hudson Station in Jersey City, NJ. The unit is located within a $30-\mathrm{ft}$ by 8 - $\mathrm{ft}$ office trailer that serves as equipment enclosure and office. No work on this task this quarter.

\section{II-9 Test Long-Term Performance at Utility Site}

\section{Results at Hudson Station.}

Routine operation of the test equipment at Hudson Station concluded November $8^{\text {th }}$ when the station was taken off-line for repairs. In all, the skid operated for roughly 1,900 hours over a 6-month period. IC traps were taken at the inlet and outlet of the skid through October $5^{\text {th }}$ on a 
weekly basis. Results showed a downward trend in mercury removal over the testing period. Table 1 summarizes the results of the 6-month field test.

In the last quarterly report, data were presented that showed acid gases such as sulfur dioxide, nitrogen dioxide, and hydrogen chloride drastically affect the performance of the noble metal sorbent. The interaction of acid gas components with the noble metal will be the subject of investigation in the upcoming quarter. A fixture containing four gold coupons was constructed and sent to Hudson Station for installation into a flue gas duct downstream of the ESP. The purpose is to expose the gold samples to actual flue gas for an extended period of time. Individual gold samples will be returned to ADA for surface analysis after approximately 2, 4, 8, and 16 weeks from installation. Surface electron microscopy (SEM) and/or X-ray photoelectron spectroscopy will be used for the analysis.

\section{Mercury/Gold Chemistry Laboratory work}

Last quarter $\mathrm{ADA}$ completed a series of tests using $\mathrm{HgCl}_{2}$ and a sorbent-coated monolith. These tests identified that interference from acid gas components limits the performance of the sorbent. This quarter a series of tests with elemental mercury were started to provide a direct comparison with data obtained by the Energy \& Environmental Research Center (EERC) using elemental mercury, simulated flue gas, and a carbon sorbent (Miller, 1998) However, initial tests showed a loss of mercury during transfer within the test apparatus when elemental mercury was used in the presence of hydrogen chloride gas. In these tests, mercury concentration decreased from the span value of $39 \mu \mathrm{g} / \mathrm{m}^{3}$ to roughly $18 \mu \mathrm{g} / \mathrm{m}^{3}$ when $\mathrm{HCl}$ gas was included in the gas mixture. We first verified that the mercury analyzer was reporting accurate gas-phase concentrations. Runs were made with a impinger containing potassium permanganate solution downstream of ADA's mercury analyzer to capture the vapor-phase mercury. The solution was analyzed for mercury using cold vapor atomic absorption (CVAA). Mercury concentrations reported by the analyzer and determined using wet chemistry were comparable, indicating that the mercury analyzer was able to detect all mercury species in the gas stream.

Given that the analyzer readings appear accurate, ADA concluded that the mercury was be retained within the tubing of the test system. Mercury loss under these conditions was unexpected since it was not mentioned in similar work presented by EERC researchers. Published tests conducted with elemental mercury and 50-ppm $\mathrm{HCl}$ in nitrogen, reported nearly $100 \%$ of the mercury was capture by the activated carbon sorbent. Those data suggest that the inlet mercury concentration was unchanged with the addition of $\mathrm{HCl}$. One difference between the ADA and EERC systems is the type of tubing used in the transfer lines. EERC uses PTFE Teflon tubing on their sorption test apparatus, whereas ADA uses electro-polished stainless steel (EP SS) tubing.

Tests were run with lengths of PTFE and EP SS connected directly to the mercury analyzer to see if mercury transport was affected by tubing materials. Equal lengths of tubing were used in runs with elemental mercury in nitrogen with and without $\mathrm{HCl}$ gas. Tubing was heat traced to maintain a temperature of $150{ }^{\circ} \mathrm{C}\left(300^{\circ} \mathrm{F}\right)$. A length of tubing was subjected to elemental mercury in nitrogen for 1.5 hours to provide data on baseline mercury holdup. A second piece of tubing was exposed to elemental mercury in nitrogen for 1.5 hours, before adding $40 \mathrm{ppm} \mathrm{HCl}$ to the gas mixture. Tubing was exposed to the gas mixture with $\mathrm{HCl}$ for one hour. Both lengths of tubing were submitted for mercury analysis. Tubing was filled with $10 \mathrm{ml}$ of $1 \%$ 
$\mathrm{HCl}$ and bromochloride and allowed to soak overnight to remove mercury sorbed on the tubing material. Rinse solution was analyzed for mercury using CVAA. Runs were also done using PTFE and EP SS tubing. The results of these tests are shown in Table 2.

Table 1. Summary of Mercury Removal by Pilot Unit at Hudson Station.

\begin{tabular}{|c|c|c|c|}
\hline $\begin{array}{c}\text { Sample } \\
\text { Date \& } \\
\text { Port \# }\end{array}$ & $\begin{array}{c}\text { Inlet } \\
\text { Hg Conc } \\
\left(\mathrm{mg} / \mathrm{m}^{3}\right)\end{array}$ & $\begin{array}{c}\text { Outlet } \\
\mathrm{Hg} \text { Conc } \\
\left(\mathrm{mg} / \mathrm{m}^{3}\right)\end{array}$ & $\begin{array}{c}\text { Removal } \\
(\%)\end{array}$ \\
\hline $6 / 8 / 99$ & 10.24 & 3.33 & $68 \%$ \\
\hline \multirow[t]{2}{*}{ Inlet SP1A } & 7.33 & 2.93 & $60 \%$ \\
\hline & 5.90 & 2.64 & $55 \%$ \\
\hline Average & & & $61 \%$ \\
\hline 6/16/99 & 25.74 & 5.27 & $80 \%$ \\
\hline \multirow[t]{2}{*}{ Inlet SP1A } & 36.64 & 5.67 & $85 \%$ \\
\hline & 13.58 & 5.26 & $61 \%$ \\
\hline Average & & & $75 \%$ \\
\hline $6 / 28 / 99$ & 21.62 & 1.74 & $\overline{92 \%}$ \\
\hline \multirow[t]{2}{*}{ Inlet SP1A } & 6.36 & 1.70 & $73 \%$ \\
\hline & 5.23 & 1.99 & $62 \%$ \\
\hline Average & & & $76 \%$ \\
\hline 7/7/99 & 6.22 & 2.74 & $56 \%$ \\
\hline \multirow[t]{2}{*}{ Inlet SP1A } & 4.32 & 2.39 & $45 \%$ \\
\hline & 4.69 & 3.08 & $34 \%$ \\
\hline Average & & & $45 \%$ \\
\hline $7 / 13 / 99$ & 2.97 & 1.43 & $52 \%$ \\
\hline \multirow[t]{2}{*}{ Inlet SP1A } & 3.02 & 2.01 & $33 \%$ \\
\hline & 2.87 & 1.75 & $39 \%$ \\
\hline Average & & & $41 \%$ \\
\hline $7 / 14 / 99$ & 3.59 & 1.38 & $62 \%$ \\
\hline \multirow[t]{2}{*}{ Inlet SP1A } & 2.42 & 1.62 & $33 \%$ \\
\hline & 2.62 & 1.92 & $27 \%$ \\
\hline Average & & & $54 \%$ \\
\hline $7 / 23 / 99$ & 5.24 & 0.97 & $81 \%$ \\
\hline \multirow[t]{2}{*}{ Inlet SP1A } & 2.64 & 1.24 & $53 \%$ \\
\hline & 2.22 & 1.14 & $49 \%$ \\
\hline Average & & & $61 \%$ \\
\hline $8 / 11 / 99$ & $\overline{3.87}$ & 3.5 & $10 \%$ \\
\hline \multirow[t]{2}{*}{ Inlet SP2 } & 3.86 & 3.81 & $1 \%$ \\
\hline & 2.97 & 2.81 & $5 \%$ \\
\hline Average & & & $5 \%$ \\
\hline $8 / 18 / 99$ & 2.51 & 2.21 & $12 \%$ \\
\hline \multirow[t]{2}{*}{ Inlet SP2 } & 2.45 & 2.12 & $13 \%$ \\
\hline & 1.81 & 1.58 & $13 \%$ \\
\hline Average & & & $13 \%$ \\
\hline $9 / 16 / 99$ & 4.05 & 4.45 & $-10 \%$ \\
\hline \multirow{2}{*}{ Inlet SP2 } & 3.33 & 3.31 & $0 \%$ \\
\hline & 3.22 & 2.89 & $10 \%$ \\
\hline Average & & & $0 \%$ \\
\hline 9/22/99 & 4.23 & 3.27 & $23 \%$ \\
\hline \multirow[t]{2}{*}{ Inlet SP2 } & 4.39 & 4.80 & $-9 \%$ \\
\hline & 4.17 & 3.89 & $7 \%$ \\
\hline Average & & & $7 \%$ \\
\hline $10 / 5 / 99$ & 6.40 & 6.41 & $0 \%$ \\
\hline \multirow{2}{*}{ Inlet SP2 } & 4.57 & 3.92 & $14 \%$ \\
\hline & 4.71 & 4.19 & $11 \%$ \\
\hline Average & & & $8 \%$ \\
\hline
\end{tabular}


Table 2 - Results of Transport Tests with Elemental Mercury in $\mathrm{N}_{2} / \mathrm{HCl}$ Gas

\begin{tabular}{|c|c|c|}
\hline Gas Mixture & PTFE Tubing & EP SS Tubing \\
\hline $\mathrm{Hg}^{\circ} / \mathrm{N}_{2}$ & $0 \mathrm{ng} \mathrm{Hg}$ & $66 \mathrm{ng} \mathrm{Hg}$ \\
\hline $\mathrm{Hg}^{\circ} / \mathrm{N}_{2} / \mathrm{HCl}$ & $44 \mathrm{ng} \mathrm{Hg}$ & $128 \mathrm{ng} \mathrm{Hg}$ \\
\hline
\end{tabular}

As shown in Table 2, little elemental mercury was retained by the PTFE tubing when only nitrogen gas was used, whereas, the EP SS retained a substantial amount of mercury. This was not unexpected since EP SS tubing does require a "conditioning" period to season the material with mercury. However, when $\mathrm{HCl}$ gas was included in the gas mixture, both PTFE and EP SS materials retained mercury. The amount of mercury retained was roughly the same for PTFE and EP SS tubing.

Nitrogen gas for these tests was taken from a membrane separation system. Therefore, some oxygen was present in the gas mixture. Additional runs were carried out using bottled nitrogen with no oxygen. Again, when $\mathrm{HCl}$ was added to the gas mixture, the mercury concentration was reduced, indicating a loss of vapor-phase mercury in the gas stream. It is suspected that nonvolatile calomel $\left(\mathrm{Hg}_{2} \mathrm{Cl}_{2}\right)$ is formed when $\mathrm{HCl}$ is added to a gas with elemental mercury.

\section{II-10 Prepare Economic Assessment for Full-Scale System}

No work on this task.

\section{II-11 Prepare Documents}

Monthly reports for September through December (status, summary, cost management, and milestone schedule) were submitted during the quarter.

\section{Project Plan for Next Quarter}

During December 1999 and into early 2000 ADA relocated its labs and offices to a new facility in Littleton, Colorado. This move consolidates ADA's facilities under one roof and will improve communication and efficiency within the company. In the near term, the move halted ADA's in-house activities and is responsible for the slowdown in effort during the recent quarter. Test equipment will be reassembled during January 2000.

The laboratory and field data from the last two quarters suggest serious limitations on the capacity of noble-metal sorbents to remove mercury from flue gas. The laboratory testing revealed that sorbent capacity was recovered by scrubbing the acid gases prior to the sorbent bed. A small scrubber will be assembled, tested, and eventually installed in the skid at Hudson later this year. The testing at Hudson will be geared to determining if the sorbent can function effectively on scrubbed flue gas. 
ADA will install gold test coupons in the flue gas duct at Hudson Station. Samples will be removed at set intervals and these coupons will be analyzed for corrosion. Any indication of corrosion will suggest that the acid gases are attacking the gold crystallites on the sorbent, resulting in poor sorbent performance. Lack of corrosion indicates a more subtle affect of flue gas on the sorbent, due perhaps to adsorbing species, which cannot be removed during regeneration.

ADA's modified mercury analyzer will be plumbed into the laboratory test system during

$2^{\text {nd }}$ Quarter FY2000. This unit will replace the laboratory monitor and allow technicians to gain more time using the new analyzer prior to the proposed field tests.

\section{References}

Miller, S.J., Dunham, G.E., Olson, E.S., Brown, T.D., "Mercury Sorbent Development in Coal-Fired Boilers," In proceedings of the Conference on Air Quality: Mercury, Trace Elements, and Particulate Matter, McLean, VA, December 1998. 